\title{
Manual Load Balancing pada Redundancy Link Menggunakan Multi-Group Hot Standby Router Protocol
}

\author{
http://dx.doi.org/10.28932/jutisi.v7i1.3403 \\ Riwayat Artikel \\ Received: 14 Februari 2021 | Final Revision: 12 Maret 2021 | Accepted: 29 Maret 2021 \\ Fajar Hariadi ${ }^{\bowtie \# 1}$ \\ Program Studi Teknik Informatika, Fakultas Sains dan Teknologi, \\ Universitas Kristen Wira Wacana Sumba \\ Jl. R. Suprapto No. 35 - Waingapu, Sumba Timur, NTT \\ fajareunkriswina.ac.id
}

\begin{abstract}
Redundancy Link is an effort to prevent network problems by providing a backup path to the main line used. Redundancy link for layer 3 network has several methods, one of which is Hot Standby Router Protocol (HSRP). HSRP itself does not have a load balancing feature, therefore in this paper we will discuss the implementation of load balancing using several HSRP Groups that created manually on four VLANs. The result is that the transition process of failover and recovery handling goes smoothly and there is rarely a loss of packets or time out, but there is an increase in the delay for a while before finally returning to normal. In addition, it was found that there was a significant difference between the failover and recovery times required when there was a network problem on one physical interface and the interface with four sub-interfaces representing the four HSRP groups for each VLAN. Where the failover handling between the two has a time difference of 6.35 seconds, while the recovery time has a time difference of 6.58 seconds.
\end{abstract}

Keywords — HSRP, Load Balancing, Redundancy Link

\section{PENDAhuluan}

Akses internet merupakan infrastruktur pendukung yang sangat penting. Hampir setiap aktivitas, baik aktivitas rumahan, perkantoran maupun pendidikan memanfaatkan koneksi internet. Terputusnya koneksi internet akan menjadi masalah yang menghambat jalannya aktivitas. Untuk meminimalisir terjadinya hal ini, dapat digunakan dua jalur sumber internet. Satu jalur merupakan jalur utama dan jalur satunya merupakan jalur alternatif apabila jalur utama terputus. Konsep ini dikenal dengan istilah redundancy link [1]. Ada tiga buah jenis redundancy link yaitu Virtual Router Redundancy Protocol (VRRP), Hot Standby Router Protocol (HSRP), dan Gateway Load Balancing Protocol (GLBP) [2].

Redundancy link menggunakan VRRP dan HSRP tidak disertai dengan fitur load balancing [2]. Sedangkan redundancy link yang menggunakan GLBP sudah langsung disertai dengan fitur load balancing [3]. Sehingga pada GLBP beban jaringan dapat dibagi ke beberapa jalur yang ada, dengan jumlah maksimal 4 jalur [4].

VRRP merupakan sebuah Protocol multi-vendor sehingga banyak perangkat dapat menggunakan VRRP, sedangkan HSRP dan GLBP merupakan milik Cisco, sehingga hanya dapat digunakan pada perangkat Cisco [5]. Hal ini membuat GLBP dapat menggunakan beberapa gateway fisik secara bersamaan, pemilihan jalur fisik aktif otomatis dan perubahan jalur otomatis apabila terjadi kesalahan pada salah satu jalur gateway [6].

GLBP sendiri memiliki performa yang lebih baik dibandingkan VRRP dan HSRP dalam hal penggunaan CPU pada router, penggunaan bandwidth untuk komunikasi antar router fisik dan kecepatan dalam mengaktifkan jalur cadangan pada saat jalur utama terputus [7]. GLBP juga memiliki kinerja traffic flow yang lebih baik dari VRRP dan HSRP [8]. Bahkan dengan adanya fitur load balancing bawaan GLBP jarang didapati terjadi packet missing walaupun salah satu jalur yang digunakan terputus [9]. Walaupun pada kasus spesifik dalam hal layanan video streaming GLBP memiliki kinerja yang lebih rendah dibandingkan HSRP [2]. Tapi dari semua hasil penelitian di atas didapati bahwa VRRP memiliki kinerja yang paling lebih rendah dibandingkan dengan HSRP dan GLBP.

Meskipun GLBP memiliki kinerja yang lebih baik, fitur load balancing secara otomatis pada beberapa kasus tidak dikehendaki. Misalnya apabila kita menginginkan beberapa VLAN harus melewati suatu firewall untuk filtering traffic yang lewat, atau apabila salah satu gateway memiliki layanan berlangganan berdasarkan kuota seperti VPN atau akses terhadap situs tertentu yang mencatat kuota berdasarkan IP Public yang digunakan oleh salah satu gateway. Selain itu 
load balancing pada GLBP bekerja dengan cara membagi traffic melalui beberapa Virtual Mac Address, hal ini berbeda dengan VRRP dan HSRP yang hanya menggunakan satu buah Virtual Mac Address [10]. Hal ini memungkinkan terjadinya hop tambahan dalam proses pengiriman paket, khususnya apabila menggunakan switch layer 3 dengan perpaduan Spanning Tree Protocol [11]. Penambahan hop ini tidak terasa apabila skala jaringan atau jumlah client sedikit, tetapi dalam skala besar penambahan hop ini membuat pengiriman paket dalam jaringan menjadi tidak optimal.

Load balancing sendiri bisa ditambahkan secara manual pada penerapan VRRP dan HSRP. Sehingga kita dapat membagi traffic data yang melalui setiap gateway dengan VLAN tertentu saja sesuai dengan kebutuhan, dan hanya membagi traffic salah gateway apabila gateway yang sudah ditetapkan mengalami trouble. Disini akan membahas bagaimana menerapkan hal tersebut diatas menggunakan HSRP, karena pada beberapa penelitian sebelumnya, HSRP memiliki kinerja yang lebih baik dibanding VRRP.

Parameter yang akan diamati adalah perbandingan jalur yang dilewati dalam kondisi normal dan kondisi salah satu gateway terputus, serta kecepatan perpindahan jalur pada saat jalur pengiriman data dialihkan.

\section{Metode PENELITIAN}

Penelitian dilakukan mengikuti tahapan seperti terlihat pada gambar 1. Tahapan Penelitian sebagai berikut:

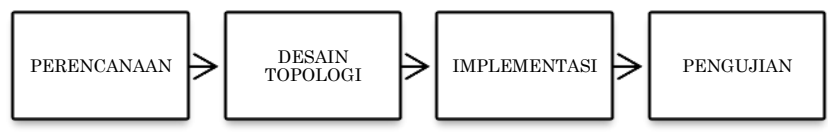

Gambar 1. Tahapan Penelitian

\section{A. Perencanaan}

Perencanaan dimulai dari menyusun jumlah dan konfigurasi VLAN. VLAN yang digunakan berjumlah 4 dengan konfigurasi pada Tabel 1. Desain VLAN.

TABEL I

DESAIN VLAN

\begin{tabular}{lll}
\hline VLAN & Nama VLAN (Network \& Gateway) \\
\hline \multirow{3}{*}{10} & \multirow{2}{*}{ DOSEN } & Net Address \\
& & Gateway \\
& & 192.168 .10 .254 \\
\hline \multirow{3}{*}{20} & \multirow{2}{*}{ PEGAWAI } & Net Address \\
& & $192.168 .20 .0 / 24$ \\
\cline { 3 - 3 } & & Gateway \\
& & 192.168 .20 .254 \\
\hline \multirow{3}{*}{30} & \multirow{2}{*}{ MAHASISWA } & Net Address \\
& & Gateway \\
& & $192.168 .30 .0 / 24$ \\
\hline
\end{tabular}

\begin{tabular}{lll}
\hline \multirow{3}{*}{$40 \quad$ TAMU } & Net Address \\
& & $192.168 .40 .0 / 24$ \\
& & Gateway \\
& & 192.168 .40 .254 \\
\hline
\end{tabular}

Desain VLAN ini akan diimplementasikan kepada switch SW1 dan SW2 dengan konfigurasi jalur access menuju hub dan trunk menuju router. Konfigurasi pada keduanya dibuat sama persis agar lebih memudahkan mengingat dan melakukan implementasi. Konfigurasi dapat dilihat pada Tabel II. Konfigurasi Tipe Port SW1 dan SW2 berikut:

TABEL II

KONFIGURASI TIPE PORT SW1 DAN SW2

\begin{tabular}{ccc}
\hline Port & VLAN & Tipe \\
\hline G0/1 & - & Trunk \\
G1/1 & 10 & Access \\
G2/1 & 20 & Access \\
G3/1 & 30 & Access \\
G4/1 & 40 & Access \\
G5/1 & - & Trunk \\
\hline
\end{tabular}

Selanjutnya perencanaan group HSRP berdasarkan VLAN dan pengaturan load balancing secara manual pada dua router ( $\mathrm{R} 1, \mathrm{R} 2)$ yang digunakan sebagai jalur internet.

TABEL III

GROUP LOAD BALANCING HSRP

\begin{tabular}{cccc}
\hline Group & VLAN & Active & Standby \\
\hline 10 & 10 & R1 & R2 \\
20 & 20 & R1 & R2 \\
30 & 30 & R2 & R1 \\
40 & 40 & R2 & R1 \\
\hline
\end{tabular}

Setiap router yang memiliki status Active akan menggunakan nilai priority 105 , sedangkan pada router mode Standby akan menggunakan nilai priority 100.

Preempt untuk setiap group diaktifkan dan dilakukan tracking terhadap jalur menuju internet dengan konfigurasi pada Tabel 4. Konfigurasi Tracking Group berikut ini:

TABEL IV

KONFIGURASI TRACKING GROUP

\begin{tabular}{ccc}
\hline Router & Group & Tracking \\
\hline \multirow{3}{*}{ R1 } & 10 & $\mathrm{G} 1 / 0$ \\
\cline { 2 - 3 } & 20 & $\mathrm{G} 1 / 0$ \\
\cline { 2 - 3 } & 30 & $\mathrm{G} 1 / 0$ \\
\cline { 2 - 3 } & 40 & $\mathrm{G} 1 / 0$ \\
\hline \multirow{3}{*}{ R2 } & 10 & $\mathrm{G} 2 / 0$ \\
\cline { 2 - 3 } & 20 & $\mathrm{G} 2 / 0$ \\
\cline { 2 - 3 } & 30 & $\mathrm{G} 2 / 0$ \\
\hline & & $\mathrm{G} 2 / 0$ \\
\hline
\end{tabular}

Tracking digunakan untuk pengalihan jalur bila jalur dari switch menuju router baik, akan tetapi dari Internet atau ISP (Internet Service Provider) yang mengalami masalah. 


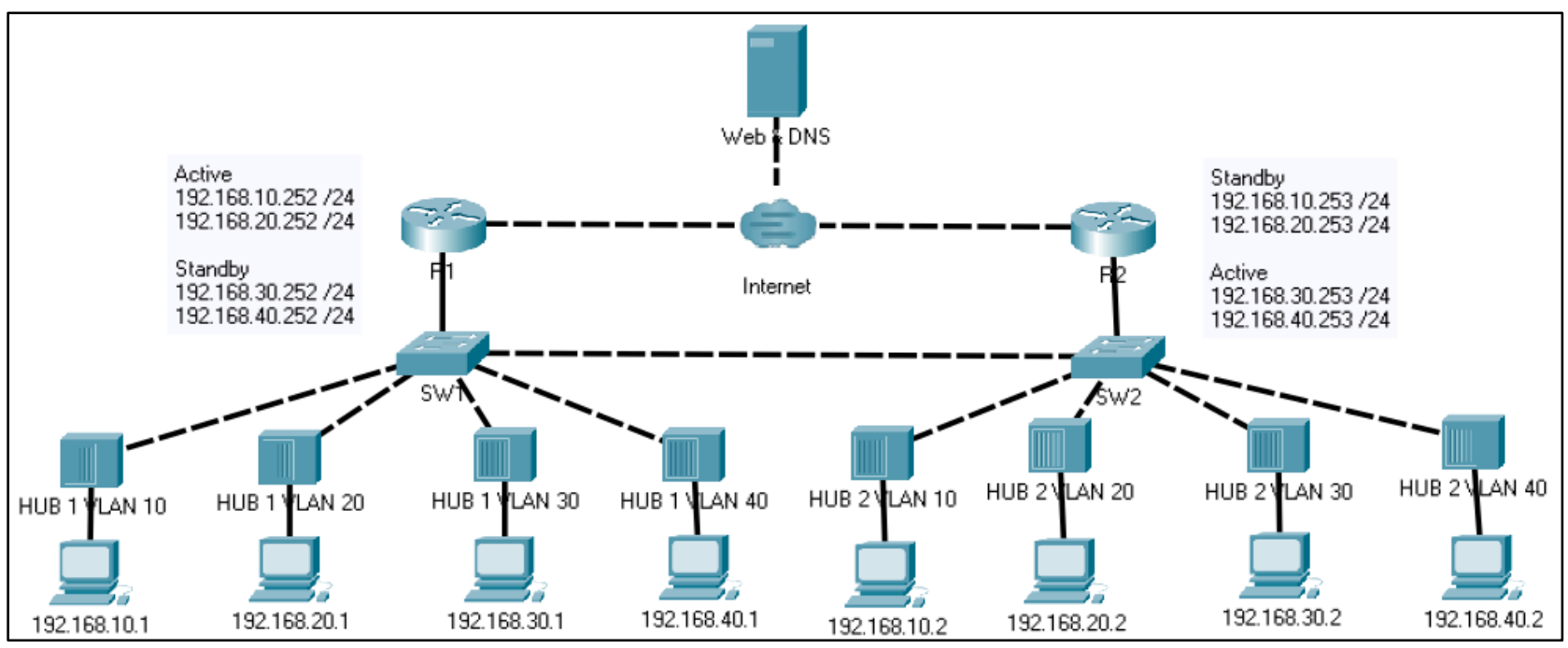

Gambar 2. Topologi Jaringan

\section{B. Desain Topologi}

Berdasarkan topologi jaringan pada Gambar 2. Topologi Jaringan, dilakukan pengaturan ip address setiap interface layer 3 yang terhubung dengan perangkat lainnya. Pengaturan ip address pada perangkat R1 dapat dilihat pada Tabel 5. Konfigurasi IP Address R1 di bawah ini:

TABEL V

KONFIGURASI IP ADDRESS R1

\begin{tabular}{ccc} 
& KONFIGURASI IP ADDRESS R1 \\
\hline Port & Link Tujuan & IP Address \\
\hline G1/0 & Internet & $20.0 .0 .2 / 8$ \\
G0/0.10 & SW1 & $192.168 .10 .250 / 24$ \\
G0/0.20 & SW1 & $192.168 .20 .250 / 24$ \\
G0/0.30 & SW1 & $192.168 .30 .250 / 24$ \\
G0/0.40 & SW1 & $192.168 .40 .250 / 24$ \\
\hline
\end{tabular}

Pada R2 konfigurasi ip address pada setiap port interface dan sub-interface terlihat pada Tabel 6. Konfigurasi IP Address R2 berikut:

TABEL VI

KONFIGURASI IP ADDRESS R2

\begin{tabular}{ccc}
\hline Port & Link Tujuan & IP Address \\
\hline G2/0 & Internet & $30.0 .0 .2 / 8$ \\
G0/0.10 & SW2 & $192.168 .10 .252 / 24$ \\
G0/0.20 & SW2 & $192.168 .20 .252 / 24$ \\
G0/0.30 & SW2 & $192.168 .30 .252 / 24$ \\
G0/0.40 & SW2 & $192.168 .40 .252 / 24$ \\
\hline
\end{tabular}

Sedangkan pada router internet, konfigurasi ip address yang dilakukan terlihat sebagai berikut:

TABEL VII

KONFIGURASI IP ADDRESS INTERNET

\begin{tabular}{ccc}
\multicolumn{3}{c}{ KONFIGURASI IP ADDRESS INTERNET } \\
\hline Port & Link Tujuan & IP Address \\
\hline G0/0 & Web \& DNS & $10.0 .0 .1 / 8$ \\
G1/0 & R1 & $20.0 .0 .1 / 8$ \\
G2/0 & R2 & $30.0 .0 .1 / 8$ \\
\hline
\end{tabular}

Ketiga router menggunakan RIP (Routing Information Protocol) sebagai routing dinamis di antara semua alamat jaringan yang terhubung dengan router. Pada router $\mathrm{R} 1$ dan R2 setiap jalur yang terhubung dengan switch (SW1 dan SW2) merupakan jalur dengan mode trunk untuk mengirimkan data ke setiap VLAN yang digunakan.

\section{Implementasi}

Penerapan dari rencana dan desain dimulai dari pembuatan VLAN pada SW1.

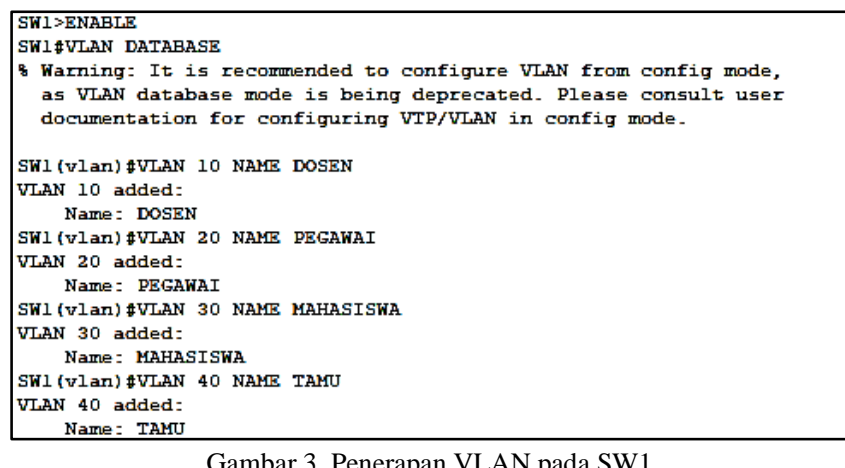

Kemudian VLAN yang sama juga diterapkan pada SW2, terlihat pada gambar 4. Penerapan VLAN pada SW2.

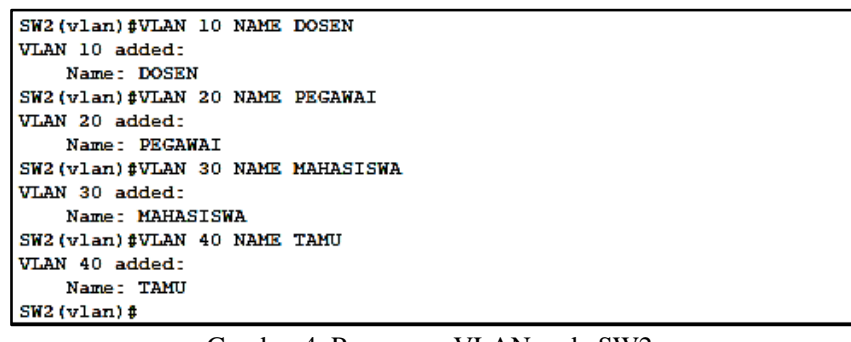

Gambar 4. Penerapan VLAN pada SW2 
Penerapan VLAN pada SW1 dan SW2 mengikuti konfigurasi pada Tabel 1. Desain VLAN pada bagian perencanaan. Setelah VLAN berhasil dibuat, selanjutnya dilakukan konfigurasi tipe port yang digunakan untuk setiap jalur yang keluar. Dimulai dari SW1 yang dapat dilihat pada Gambar 5. Konfigurasi Tipe Port SW1 berikut ini:

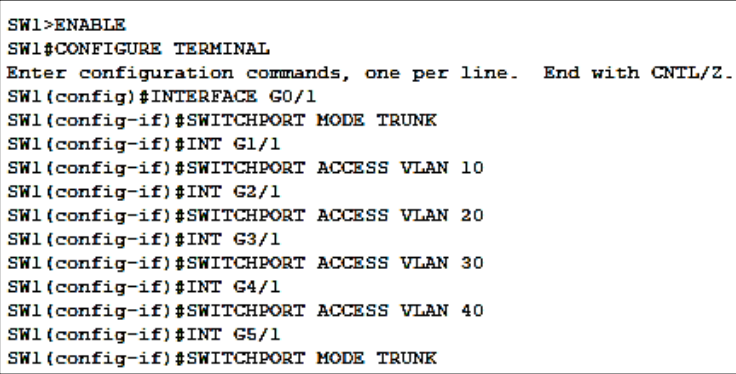

Gambar 5. Penerapan Tipe Port pada SW1

Konfigurasi yang sama juga dilakukan pada SW2, terlihat pada Gambar 6. Penerapan Tipe Port pada SW2 berikut:

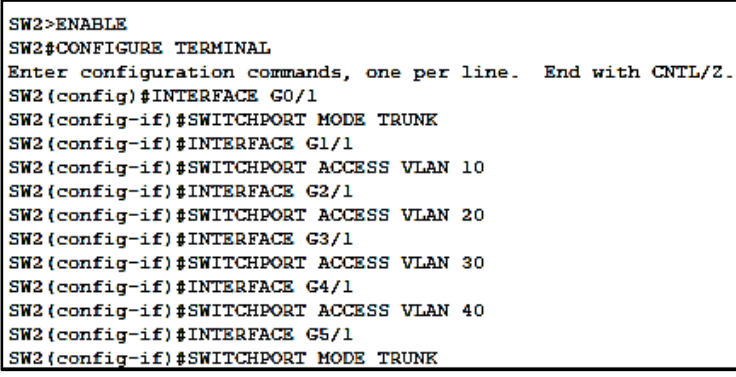

Selanjutnya setiap perangkat layer 3 diberikan ip address. Dimulai dengan pemberian ip address pada interface dan sub-interface pada R1. Khusus sub-interface, sebelum diberikan ip address akan diaktifkan terlebih dahulu encapsulation DotlQ dengan nomor VLAN yang sesuai. Proses pemberian ip address dapat dilihat pada Gambar 7. Konfigurasi IP Address R1 berikut ini:

RI>ENABLE

R1\#CONFIGURE TERMINAI

Enter configuration commands, one per line. End with CNTL/z.

R1 (config) \#INTERFACE G1/0

RI(config-if) \#IP ADDRESS 20-0.0.2 255 - 0.0.0

R1 (config-if) \#INTERFACE G0/0.10

R1 (config-subif) \#ENCAPSULATION DOT1Q 10

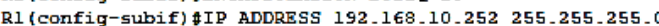

Rl (config-subif) \#INTERFACE G0 10.20

R1 (config-subif) \#ENCAPSULATION DOT10 20

R1 (config-subif) \#IP ADDRESS 192 _.168.20.252 255.255.255.0

Rl (config-subif) \#INTERFACE G0/0.30

R1 (config-subif) \#ENCAPSULATION DOT10 30

R1 (config-subif) \#IP ADDRESS $192.168 .30 .252 \quad 255.255 .255 .0$

R1 (config-subif) \#IP ADDRESS 192.16

R1 (config-subif) \#INTERFACE G0/0 40

R1 (config-subif) \#ENCAPSULATION DOT1Q 40
R1 (config-subif) \#IP ADDRESS $192.168 .40 .252 \quad 255.255 .255 .0$

Gambar 7. Konfigurasi IP Address R1

Pada router R2 dilakukan konfigurasi sesuai dengan Tabel

7. Konfigurasi IP Address R2. Proses Konfigurasi dapat dilihat pada Gambar 8. Konfigurasi IP Address R2 berikut ini:

\section{R2 $>$ ENABLE}

R2\#CONFIGURE TERMINAI

Enter configuration commands, one per line. End with CNTL/Z,

R2 (config) \#INTERFACE G2 20

R2 (config-if) IP ADDRESS 30-0.0.2 255.0 .0 .0

R2 (config-if) \#INTERFACE G0/0.10

R2 (config-subif) \#ENCAPSULATION DOT1Q 10

R2 (config-subif) \#IP ADDRESS $192.168 .10 .253 \quad 255.255 .255 .0$

R2 (config-subif) \#INTERFACE G0 $\%$. 20

R2 (config-subif) \#ENCAPSULATION DOT1Q 20

R2 (config-subif) \#IP ADDRESS $192 \ldots 168.20 .253255 .255 .255 .0$

R2 (config-subif) \#INTERFACE G0/0 30

R2 (config-subif) \#ENCAPSULATION DOT1Q 30

R2 (config-subif) \#IP ADDRESS 192.168_30 253255.255 .255 .0

R2 (config-subif) \#INTERFACE G0/0 40

R2 (config-subif) \#ENCAPSULATION DOT10 40

R2 (config-subif) \#IP ADDRESS $192 \ldots 168,40.253255 .255 .255$

R2 (config-subif) \#

Gambar 8. Konfigurasi IP Address R2

Router terakhir yang dikonfigurasi adalah router yang berperan sebagai internet. Skema konfigurasi yang dilakukan sesuai dengan Tabel 8. Konfigurasi IP Address Internet. Proses konfigurasi dapat dilihat pada Gambar 9. Konfigurasi IP Address Internet berikut ini:

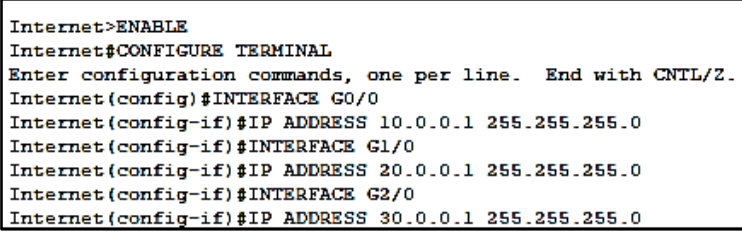

Gambar 9. Konfigurasi IP Address Internet

Setelah semua interface dan sub-interface memiliki ip address, maka selanjutnya adalah mengaktifkan routing. Routing yang digunakan adalah Routing Information Protocol (RIP) versi 2. Langkah ini dimulai dari R1 dimana proses penerapannya dapat dilihat pada Gambar 10. RIP pada R1 berikut ini:

\section{RI> \\ RI $\gg$ ENABLE}

RI\#CONFIGURE TERMINAI

Enter configuration cormands, one per line. End with CNTL/Z.

RI (config) AROUTER RIP

RI (config-router) \#VERSION

R1 (config-router) \#NETWORK 20-0.0-0

Rl (config-router) \#NETWORK 192.168 .10 .0

R1 (config-router) \#NETWORK 192 . 168.20 .0

Rl (config-router) \#NETWORK 192.168 .30 .0

Rl (config-router) \#NETWORK 192.168 .40 .0

Rl (config-router)

\section{Gambar 10. RIP pada R1}

RIP merupakan salah satu routing dinamis, dimana kita harus mendaftarkan setiap alamat jaringan yang terhubung langsung dengan router. Hal yang sama juga dilakukan pada router $\mathrm{R} 2$. 


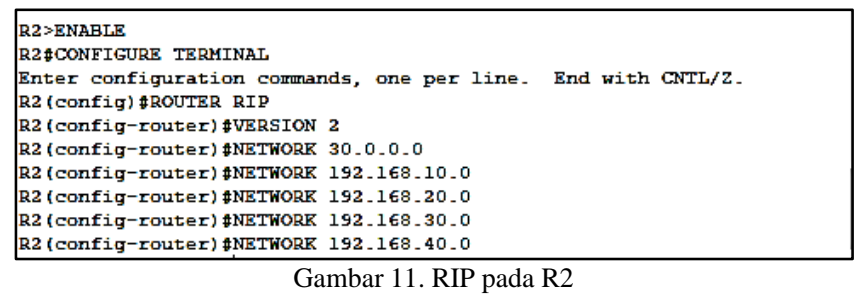

Penerapan RIP pada router yang terakhir dilakukan pada router Internet yang dapat dilihat pada Gambar 12. RIP pada Internet

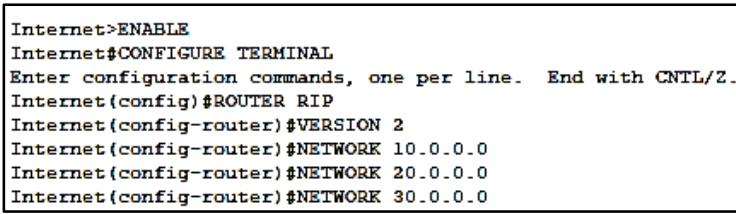

Gambar 12. RIP pada Internet

Setelah RIP terpasang pada ketiga router dan semua router sudah saling berbagi routing table. Maka selanjutnya membuat group load balancing sesuai Tabel 4. Group Load Balancing HSRP, mengaktifkan tracking sesuai Tabel 5. Konfigurasi Tracking Group, memberi nilai priority 105 untuk router active dan nilai priority 100 untuk router standby serta mengaktifkan preempt untuk setiap group pada R1 dan R2. Dimana penerapan pada R1 dapat dilihat pada Gambar 13. HSRP pada R1 di bawah ini:

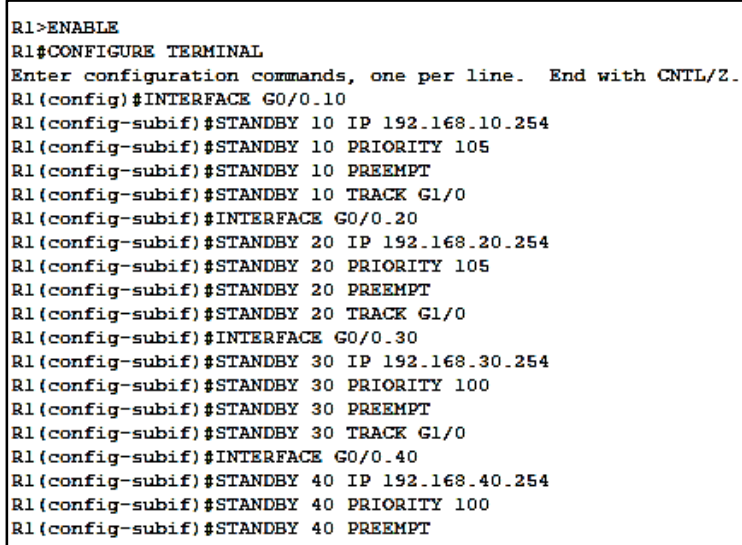

Gambar 13. HSRP pada R1

Berikut ini adalah hasil validasi terhadap konfigurasi yang dilakukan pada R1:

\section{$R 1>E N A B L E$ \\ RI\#SHOW STANDBY}

GigabitEthernet0/0.10 - Group 10

State is Active

11 state changes, last state change 05:15:07

Virtual IP address is 192.168.10.254

Active virtual MAC address is 0000.0C07.ACOA
Local virtual MAC address is 0000.0C07.ACOA (v1

default)

Hello time $3 \mathrm{sec}$, hold time $10 \mathrm{sec}$

Next hello sent in 2.292 secs

Preemption enabled

Active router is local

Standby router is 192.168.10.253

Priority 105 (configured 105)

Track interface GigabitEthernet $1 / 0$ state Up decrement 10

Group name is hsrp-Gig-10 (default)

GigabitEthernet0/0.20 - Group 20

State is Active

9 state changes, last state change 05:14:46

Virtual IP address is 192.168.20.254

Active virtual MAC address is 0000.0C07.AC14

Local virtual MAC address is 0000.0C07.AC14 (v1

default)

Hello time $3 \mathrm{sec}$, hold time $10 \mathrm{sec}$

Next hello sent in 0.747 secs

Preemption enabled

Active router is local

Standby router is 192.168.20.253

Priority 105 (configured 105)

Track interface GigabitEthernet $1 / 0$ state Up decrement 10

Group name is hsrp-Gig-20 (default)

GigabitEthernet0/0.30 - Group 30

State is Standby

35 state changes, last state change 05:22:29

Virtual IP address is 192.168.30.254

Active virtual MAC address is 0000.0C07.AC1E

Local virtual MAC address is 0000.0C07.AC1E (v1

default)

Hello time $3 \mathrm{sec}$, hold time $10 \mathrm{sec}$

Next hello sent in 2.101 secs

Preemption enabled

Active router is 192.168.30.253, priority 105 (expires in 7 $\mathrm{sec}$ )

MAC address is 0000.0C07.AC1E

Standby router is local

Priority 100 (default 100)

Track interface GigabitEthernet $1 / 0$ state Up decrement 10

Group name is hsrp-Gig-30 (default)

GigabitEthernet0/0.40 - Group 30

State is Active

8 state changes, last state change 05:10:20

Virtual IP address is 192.168.30.254

Active virtual MAC address is 0000.0C07.AC1E

Local virtual MAC address is 0000.0C07.AC1E (v1 default)

Hello time $3 \mathrm{sec}$, hold time $10 \mathrm{sec}$

Next hello sent in 0.754 secs

Preemption enabled

Active router is local

Standby router is unknown

Priority 100 (default 100)

Group name is hsrp-Gig-30 (default) 
GigabitEthernet0/0.40 - Group 40

State is Standby

18 state changes, last state change 05:22:30

Virtual IP address is 192.168.40.254

Active virtual MAC address is 0000.0C07.AC28

Local virtual MAC address is 0000.0C07.AC28 (v1

default)

Hello time $3 \mathrm{sec}$, hold time $10 \mathrm{sec}$

Next hello sent in 2.524 secs

Preemption enabled

Active router is 192.168.40.253

Standby router is local

Priority 100 (default 100)

Track interface GigabitEthernet $1 / 0$ state Up decrement 10

Group name is hsrp-Gig-40 (default)

Setelah load balancing HSRP pada R1 telah selesai dilakukan dan divalidasi, maka dilanjutkan dengan mengkonfigurasi R2 agar kerja sama antar router dapat dibentuk. Proses konfigurasi pada R2 terlihat pada Gambar 14. HSRP pada R2 di bawah ini:

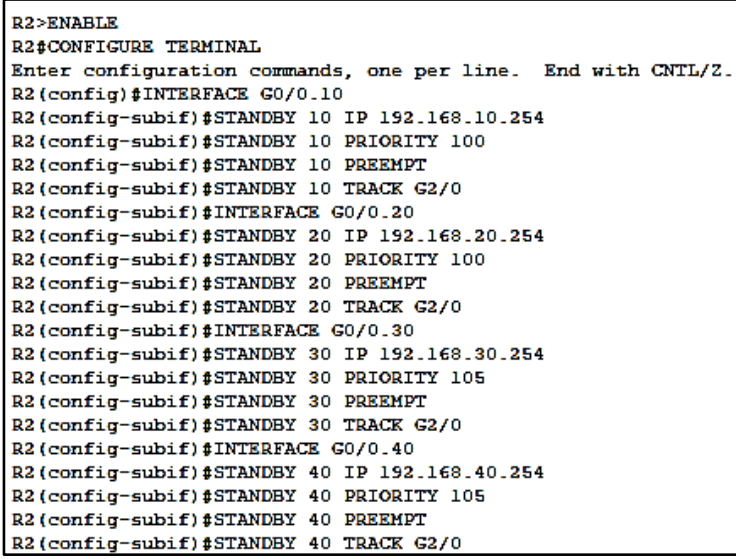

Hasil validasi HSRP terhadap konfigurasi yang dilakukan pada R2:

\section{$R 2>E N A B L E$ \\ R2\#SHOW STANDBY}

GigabitEthernet0/0.10 - Group 10

State is Standby

12 state changes, last state change 05:21:46

Virtual IP address is 192.168.10.254

Active virtual MAC address is 0000.0C07.ACOA

Local virtual MAC address is 0000.0C07.ACOA (v1 default)

Hello time $3 \mathrm{sec}$, hold time $10 \mathrm{sec}$

Next hello sent in 1.895 secs

Preemption enabled

Active router is 192.168.10.252
Standby router is local

Priority 100 (default 100)

Track interface GigabitEthernet $2 / 0$ state Up decrement 10

Group name is hsrp-Gig-10 (default)

GigabitEthernet0/0.20 - Group 20

State is Standby

12 state changes, last state change 05:21:44

Virtual IP address is 192.168.20.254

Active virtual MAC address is 0000.0C07.AC14

Local virtual MAC address is 0000.0C07.AC14 (v1

default)

Hello time $3 \mathrm{sec}$, hold time $10 \mathrm{sec}$

Next hello sent in 0.142 secs

Preemption enabled

Active router is 192.168.20.252

Standby router is local

Priority 100 (default 100)

Track interface GigabitEthernet2/0 state Up decrement 10

Group name is hsrp-Gig-20 (default)

GigabitEthernet0/0.30 - Group 30

State is Active

15 state changes, last state change 05:21:45

Virtual IP address is 192.168.30.254

Active virtual MAC address is 0000.0C07.AC1E

Local virtual MAC address is 0000.0C07.AC1E (v1 default)

Hello time $3 \mathrm{sec}$, hold time $10 \mathrm{sec}$

Next hello sent in 2.376 secs

Preemption enabled

Active router is local

Standby router is 192.168.30.252, priority 100 (expires in $7 \mathrm{sec}$ )

Priority 105 (configured 105)

Track interface GigabitEthernet2/0 state Up decrement 10

Group name is hsrp-Gig-30 (default)

GigabitEthernet0/0.40 - Group 40

State is Active

12 state changes, last state change 05:21:54

Virtual IP address is 192.168.40.254

Active virtual MAC address is 0000.0C07.AC28

Local virtual MAC address is 0000.0C07.AC28 (v1 default)

Hello time $3 \mathrm{sec}$, hold time $10 \mathrm{sec}$

Next hello sent in 2.369 secs

Preemption enabled

Active router is local

Standby router is 192.168 .40 .252 , priority 100 (expires in $6 \mathrm{sec}$ )

Priority 105 (configured 105)

Track interface GigabitEthernet2/0 state Up decrement 10

Group name is hsrp-Gig-40 (default) 
Sampai dengan tahap ini dilakukan pemeriksaan terhadap semua konfigurasi yang telah dilakukan dengan memastikan seluruh konfigurasi VLAN sudah sesuai rancangan, dan seluruh PC telah diberikan ip address, subnet mask dan gateway yang sesuai. Apabila semua telah sesuai maka proses implementasi HSRP telah selesai dilakukan. Tahap selanjutnya adalah menentukan skenario pengujian sebagai acuan dalam mengambil data yang diperlukan.

\section{Pengujian}

Pengujian yang dilakukan ada tiga jenis, yang pertama digunakan untuk mengamati jalur pengiriman paket load balancing, pengujian kedua digunakan untuk mengamati kecepatan redundancy link mengatasi permasalahan pada jalur utama dan pengujian ketiga digunakan untuk mengamati kecepatan redundancy link kembali ke jalur utama apabila jalur utama sudah kembali terhubung.

Tipe pengujian pertama dilakukan dengan mengamati jalur pengiriman paket dengan melakukan traceroute dari seluruh PC Client yang berjumlah 8 buah menuju PC Web Server yang sekaligus menjadi DNS Server. Skenario pengujian traceroute dapat dilihat pada Tabel 8. Skenario Pengujian Traceroute berikut:

TABEL VIII

\begin{tabular}{|c|c|c|}
\hline \multicolumn{3}{|c|}{$\begin{array}{c}\text { TABEL VIII } \\
\text { SKENARIO PENGUJIAN TRACEROUTE }\end{array}$} \\
\hline VLAN & IP Asal & IP Tujuan \\
\hline \multirow{2}{*}{10} & 192.168.10.1 & \multirow{2}{*}{ 10.0.0.2 } \\
\hline & 192.168 .10 .2 & \\
\hline \multirow{2}{*}{20} & 192.168.20.1 & \multirow{2}{*}{ 10.0.0.2 } \\
\hline & 192.168 .20 .2 & \\
\hline \multirow{2}{*}{30} & 192.168 .30 .1 & \multirow{2}{*}{ 10.0.0.2 } \\
\hline & 192.168 .30 .2 & \\
\hline \multirow{2}{*}{40} & 192.168 .40 .1 & \multirow{2}{*}{ 10.0.0.2 } \\
\hline & 192.168 .40 .2 & \\
\hline
\end{tabular}

Skenario ini akan dilakukan berulang pada tiga kondisi berikut:

1. Normal

2. Jalur dari R1 ke Internet terputus

3. Jalur dari R2 ke Internet terputus

Selain traceroute akan dilakukan pula pengamatan pada mode simulasi Cisco Packet Tracer untuk melihat jalur pengiriman paket data yang digunakan.

Tipe pengujian kedua dilakukan dengan mengamati selisih waktu pada debug log router R1 \& R2 pada saat terjadi pemutusan koneksi jalur utama dan perubahan state dari standby menjadi active pada jalur backup setiap group.

Pada tipe pengujian ketiga mirip seperti tipe pengujian kedua, namun yang diamati adalah selisih waktu antara jalur utama yang tadinya terputus menjadi tersambung kembali dengan perubahan state jalur utama dari standby menjadi active kembali.

\section{HASIL DAN PEMBAHASAN}

Proses pengujian pertama dapat dilihat pada Gambar 15 . Contoh Traceroute di bawah ini:

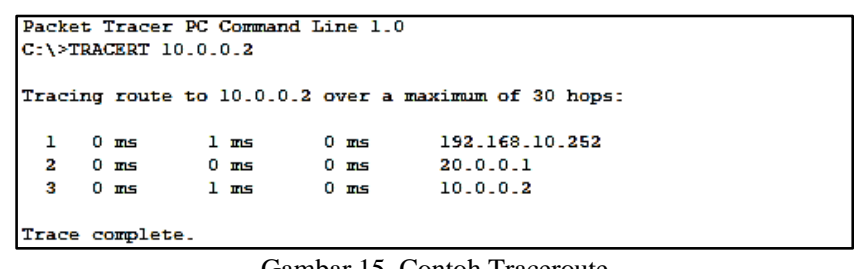

Pada gambar terlihat proses traceroute dari PC dengan ip address 192.168.10.1 yang merupakan VLAN 10 dan Group HSRP 10 melewati jalur 192.168.10.252 pada interface R1 yang merupakan jalur utamanya. Data yang didapat pada saat pengujian berdasarkan skenario pengujian terlihat pada Tabel 9. Data Traceroute berikut ini:

TABEL IX DATA TRACEROUTE

\begin{tabular}{|c|c|c|c|}
\hline VLAN & IP Asal & IP Tujuan & Hop \\
\hline \multirow{2}{*}{10} & 192.168 .10 .1 & \multirow{2}{*}{10.0 .0 .2} & $\mathrm{R} 1$ \\
\hline & 192.168 .10 .2 & & $\mathrm{R} 1$ \\
\hline \multirow{2}{*}{20} & 192.168.20.1 & \multirow{2}{*}{10.0 .0 .2} & $\mathrm{R} 1$ \\
\hline & 192.168 .20 .2 & & $\mathrm{R} 1$ \\
\hline \multirow{2}{*}{30} & 192.168 .30 .1 & \multirow{2}{*}{10.0 .0 .2} & $\mathrm{R} 2$ \\
\hline & 192.168 .30 .2 & & R2 \\
\hline \multirow{2}{*}{40} & 192.168 .40 .1 & \multirow{2}{*}{10.0 .0 .2} & R2 \\
\hline & 192.168 .40 .2 & & $\mathrm{R} 2$ \\
\hline
\end{tabular}

Dari tabel ini dapat dilihat load balancing secara manual sudah berhasil membagi VLAN 10 dan 20 melewati R1 sebagai jalur utamanya dan R2 sebagai jalur cadangan. Sedangkan VLAN 30 dan 40 melewati R2 yang merupakan jalur utamanya dengan R1 sebagai jalur cadangan.

Proses pengujian kedua dapat dilihat pada Gambar 16. Contoh Pemutusan Jalur Utama di bawah ini:

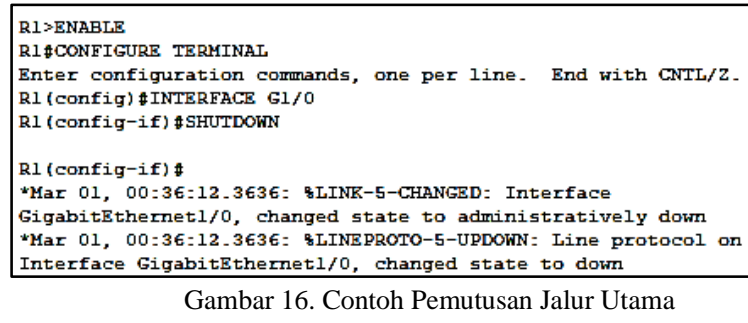

Data waktu pada saat jalur utama terputus ini akan menjadi acuan dalam selisih perhitungan ketika terjadi perubahan jalur cadangan dari standby menjadi active seperti terlihat pada Gambar 17. Contoh Standby Jadi Active

R2>

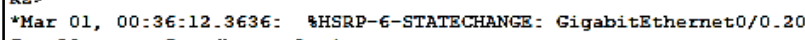
Grp 20 state Standby $\rightarrow$ Active

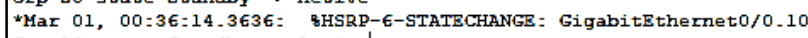
Grp 10 state Standby $\rightarrow$ Active

Gambar 17. Contoh Standby Jadi Active 
Pada gambar 17 terlihat jalur cadangan Group 10 berubah menjadi active terlihat pada timestamp 00:36:14.3636 (hh:mm:ss.ms) sedangkan jalur utama terputus pada gambar 16 pada waktu 00:36:12.3636 (hh:mm:ss.ms), dari selisih waktu ini berarti HSRP mulai mengaktifkan jalur cadangan untuk Group 10 selama 3 detik setelah jalur utama terputus. Sedangkan pada Group 20 jalur cadangan active pada timestamp 00:36:12.3636 (hh:mm:ss.ms) sehingga selisih waktu yang diperlukan Group 20 pada contoh kejadian ini adalah 0 detik, atau jalur cadangan langsung active pada saat jalur utama terputus. Langkah ini dilakukan berulang sebanyak 5 kali untuk masing-masing interface pada jalur utama setiap group.

Jalur utama Group HSRP 10 merupakan router interface G1/0 dan G0/0 pada router R1. Interface G1/0 merupakan interface yang terhubung dengan Internet, sedangkan interface G1/0 merupakan interface yang memiliki 4 subinterface untuk setiap VLAN 10, 20, 30 dan 40.

Pengujian dilakukan dengan memutuskan salah satu dari kedua interface ini secara bergantian masing-masing sebanyak 5 kali.

Data yang diperoleh dapat dilihat pada Tabel 10. Data Failover Group HSRP 10 berikut ini:

TABEL X

DATA FAILOVER GROUP HSRP 10

\begin{tabular}{cc}
\hline INTERFACE & WAKTU FAILOVER (s) \\
\hline \multirow{3}{*}{ G1/0 } & 1.00 \\
\cline { 2 - 2 } & 2.00 \\
\cline { 2 - 2 } & 0.00 \\
\cline { 2 - 2 } & 2.00 \\
\hline \multirow{3}{*}{ G0/0 } & 2.00 \\
\cline { 2 - 2 } & 8.01 \\
\cline { 2 - 2 } & 9.00 \\
\hline
\end{tabular}

Kolom interface pada tabel merupakan interface yang dimatikan sebagai simulasi jalur utama terputus. Sedangkan waktu failover merupakan waktu yang diperlukan jalur cadangan (standby) untuk berubah menjadi jalur pengiriman data (active).

Terlihat bahwa failover lebih cepat dilakukan apabila jalur putus adalah jalur interface G1/0 yang terhubung dengan internet dengan rata-rata waktu sebesar 1.40 detik.

Sedangkan apabila jalur yang putus adalah jalur lokal yang memiliki sub-interface yang mewakili 4 Group HSRP dengan rata-rata waktu 8.20 detik.

Pengujian yang sama dilakukan terhadap Group HSRP 20. Data pengujian terlihat pada Tabel 11. Data Failover Group HSRP 20 di bawah ini:

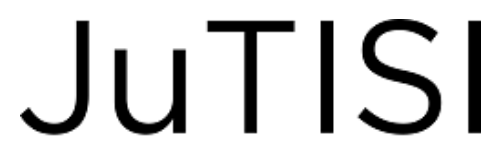

TABEL XI

DATA FAILOVER GROUP HSRP 20

\begin{tabular}{cc}
\hline INTERFACE & \multicolumn{1}{c}{ WAKTU FAILOVER $(\mathbf{s})$} \\
\hline \multirow{3}{*}{ G1/0 } & 1.00 \\
\cline { 2 - 2 } & 0.98 \\
\cline { 2 - 2 } & 0.00 \\
\cline { 2 - 2 } & 1.00 \\
\cline { 2 - 2 } G0/0 & 1.00 \\
\cline { 2 - 2 } & 6.06 \\
\cline { 2 - 2 } & 8.00 \\
\hline & 8.01 \\
\hline
\end{tabular}

Data yang didapat tidak jauh beda dengan data pengujian group HSRP 10, dimana pada pengujian group HSRP 20 waktu failover memerlukan waktu lebih lama apabila interface yang mati adalah interface yang memiliki 4 subinterface dengan waktu rata-rata failover sebesar 7.64 detik, sedangkan apabila yang mati adalah interface yang terhubung dengan internet (G0/0) waktu rata-rata failover yang didapat sebesar 0.80 detik.

Selanjutnya pengujian failover untuk group HSRP 30 dan 40 dilakukan pada router $\mathrm{R} 2$ dengan interface $\mathrm{G} 2 / 0$ sebagai interface yang terhubung dengan internet dan interface $\mathrm{G} 0 / 0$ sebagai interface yang memiliki 4 group HSRP.

Data pengujian failover group HSRP 30 yang didapat dapat dilihat pada Tabel 12. Data Failover Group HSRP 30 berikut ini:

TABEL XII

DATA FAILOVER GROUP HSRP 30

\begin{tabular}{cc}
\hline INTERFACE & \multicolumn{1}{c}{ WAKTU FAILOVER (s) } \\
\hline \multirow{3}{*}{ G2/0 } & 0.00 \\
\cline { 2 - 2 } & 2.24 \\
\cline { 2 - 2 } & 3.26 \\
\cline { 2 - 2 } & 3.00 \\
\cline { 2 - 2 } G0/0 & 1.00 \\
\cline { 2 - 2 } & 7.00 \\
\cline { 2 - 2 } & 8.33 \\
\hline
\end{tabular}

Pada pengujian Group HSRP 30 kecepatan rata-rata jalur cadangan aktif apabila yang terputus adalah interface yang terhubung dengan internet adalah 3.05 detik sedangkan apabila yang terputus adalah interface pada jalur lokal, waktu rata-rata yang diperlukan adalah 8.32 detik.

Pengujian failover yang terakhir pada group HSRP 40 terdapat pada Tabel 13. Data Failover Group HSRP 40:

TABEL XII

DATA FAILOVER GROUP HSRP 40

\begin{tabular}{cc}
\hline INTERFACE & WAKTU FAILOVER (s) \\
\cline { 2 - 2 } G $2 / 0$ & 0.18 \\
\cline { 2 - 2 } & 2.24 \\
\cline { 2 - 2 } & 2.00 \\
& 2.00
\end{tabular}




\begin{tabular}{cc}
\hline INTERFACE & WAKTU FAILOVER (s) \\
\hline & 0.30 \\
\hline \multirow{3}{*}{$\mathrm{G} 0 / 0$} & 7.00 \\
\cline { 2 - 2 } & 8.00 \\
\cline { 2 - 2 } & 7.00 \\
\cline { 2 - 2 } & 7.00 \\
\hline
\end{tabular}

Hasil rata-rata waktu yang diperlukan untuk mengaktifkan jalur cadangan adalah 1.35 detik apabila interface yang terhubung internet putus, sedangkan apabila interface pada jalur lokal yang terputus memerlukan waktu rata-rata sebesar 7.39 detik.

Dari keempat pengujian pada Group HSRP setiap kali jalur lokal dengan 4 sub-interface yang terputus memakan waktu rata-rata 7.71 detik, sedangkan apabila interface yang mati adalah interface yang terhubung dengan internet, waktu yang diperlukan memiliki rata-rata 1.36 detik.

Selama keempat pengujian jalur dengan 4 sub-interface selalu memakan waktu lebih lama dibandingkan dengan jalur yang memiliki satu interface.

Setelah pengujian failover untuk masing-masing group HSRP, pengujian selanjutnya adalah mengaktifkan kembali jalur terputus dan mengamati waktu yang diperlukan router untuk kembali mengirim paket menggunakan jalur utama dari masing-masing group.

Data pengujian group HSRP 10 dapat dilihat pada Tabel 14. Data Recovery Group HSRP 10 di bawah ini:

TABEL XIV

DATA RECOVERY GROUP HSRP 10

\begin{tabular}{|c|c|}
\hline INTERFACE & WAKTU FAILOVER (s) \\
\hline \multirow{5}{*}{$\mathrm{G} 2 / 0$} & 2.00 \\
\hline & 0.00 \\
\hline & 0.00 \\
\hline & 2.00 \\
\hline & 1.00 \\
\hline \multirow{5}{*}{ G0/0 } & 8.01 \\
\hline & 8.90 \\
\hline & 7.00 \\
\hline & 8.00 \\
\hline & 8.00 \\
\hline
\end{tabular}

Berdasarkan data pengujian didapati bahwa untuk kembali menggunakan jalur utama dimana perubahan status jalur utama dari standby menjadi active apabila interface yang terhubung internet mati kemudian hidup kembali memiliki rata-rata waktu 1.00 detik, bahkan pada beberapa pengujian jalur langsung menjadi aktif tanpa ada waktu tunggu. Sedangkan apabila interface lokal dengan 4 sub-interface yang mewakili 4 group HSRP yang mati dan hidup kembali waktu rata-rata yang diperlukan adalah 7.98 detik.

Pengujian yang sama dilakukan pada group berikutnya, yaitu group HSRP 20 memberikan hasil yang terlihat pada Tabel 15. Data Recovery Group HSRP 10 berikut:
TABEL XV

DATA RECOVERY GROUP HSRP 20

\begin{tabular}{lc} 
INTERFACE & WAKTU FAILOVER (s) \\
\cline { 2 - 2 } & 2.00 \\
\cline { 2 - 2 } $\mathrm{G} 2 / 0$ & 0.00 \\
\cline { 2 - 2 } & 2.00 \\
\cline { 2 - 2 } & 2.03 \\
\cline { 2 - 2 } $\mathrm{G} 0 / 0$ & 1.00 \\
\cline { 2 - 2 } & 8.01 \\
\cline { 2 - 2 } & 10.90 \\
\hline
\end{tabular}

Rata-rata waktu yang diperlukan untuk recovery jalur utama apabila interface yang mati dan hidup kembali adalah interface yang terhubung dengan internet adalah 1.41 detik. Sedangkan apabila interface yang mati adalah interface lokal, waktu rata-rata didapat 9.33 detik.

Untuk pengujian group HSRP 30 dan 40, pengujian dilakukan terhadap pada router $\mathrm{R} 2$ dengan interface $\mathrm{G} 2 / 0$ sebagai interface yang terhubung internet dan interface $\mathrm{G} 2 / 2$ yang merupakan interface lokal dengan 4 group HSRP yang diwakili oleh 4 sub-interface. Data pengujian yang didapat untuk group HSRP 30 dapat dilihat pada Tabel 16. Data Recovery Group HSRP 30 berikut:

TABEL XIV

DATA RECOVERY GROUP HSRP 30

\begin{tabular}{cc}
\hline INTERFACE & \multicolumn{2}{c}{ WAKTU FAILOVER (s) } \\
\hline \multirow{3}{*}{ G2/0 } & 3.00 \\
\cline { 2 - 2 } & 4.25 \\
\cline { 2 - 2 } & 0.00 \\
\cline { 2 - 2 } & 2.00 \\
\hline \multirow{3}{*}{ G0/0 } & 1.00 \\
\cline { 2 - 2 } & 9.00 \\
\cline { 2 - 2 } & 8.66 \\
\cline { 2 - 2 } & 9.00 \\
\hline
\end{tabular}

Waktu rata-rata yang didapat apabila interface $\mathrm{G} 0 / 2$ pada R2 yang mati kemudian hidup kembali adalah 2.05 detik, sedangkan apabila interface G0/0 yang mati lalu hidup kembali memakan waktu rata-rata 8.32 detik agar jalur pengiriman data kembali ke jalur utama.

Uji recovery terakhir pada group HSRP 40 dapat dilihat pada Tabel 17. Data Recovery Group HSRP 40 di bawah ini:

TABEL XVII

DATA RECOVERY GROUP HSRP 40

\begin{tabular}{cc}
\hline INTERFACE & WAKTU FAILOVER (s) \\
\hline & 2.00 \\
\cline { 2 - 2 } $\mathrm{G} 2 / 0$ & 2.25 \\
\cline { 2 - 2 } & 3.00 \\
\cline { 2 - 2 } & 1.00 \\
\hline $\mathrm{G} 0 / 0$ & 1.00 \\
\hline
\end{tabular}




\begin{tabular}{rr}
\hline & 7.00 \\
\cline { 2 - 2 } & 8.00 \\
\cline { 2 - 2 } & 1.97 \\
\hline
\end{tabular}

Hasil yang didapat apabila interface G2/0 yang mati dan hidup kembali memerlukan waktu rata-rata sebesar 1.85 detik agar pengiriman data kembali melalui jalur utama. Sedangkan apabila interface G0/0 yang mati dan hidup kembali, memerlukan waktu rata-rata 7.00 detik.

Keempat pengujian pada 4 group HSRP apabila interface fisik yang terhubung dengan internet yang mati dan hidup kembali memiliki waktu rata-rata recovery 1.58 detik. Sedangkan apabila jalur yang mati dan hidup kembali adalah jalur lokal yang menangani 4 group HSRP yang diwakili oleh 4 sub-interface yang berbeda memerlukan rata-rata waktu lebih lama sebesar 7.00 detik.

Baik dari pengujian failover dan recovery hal ini selalu sejalan, dimana apabila yang mengalami masalah adalah interface yang menangani keempat group akan selalu memakan waktu lebih lama untuk failover dan recovery. Sedangkan apabila jalur yang mengalami masalah adalah jalur interface fisik yang terhubung internet, failover dan recovery dapat lebih cepat dilakukan.

Dari semua pengujian, baik pengujian failover maupun pengujian recovery jarang didapati adanya request time out atau packet missing seperti pada Gambar 18. Pengujian Request Time Out.

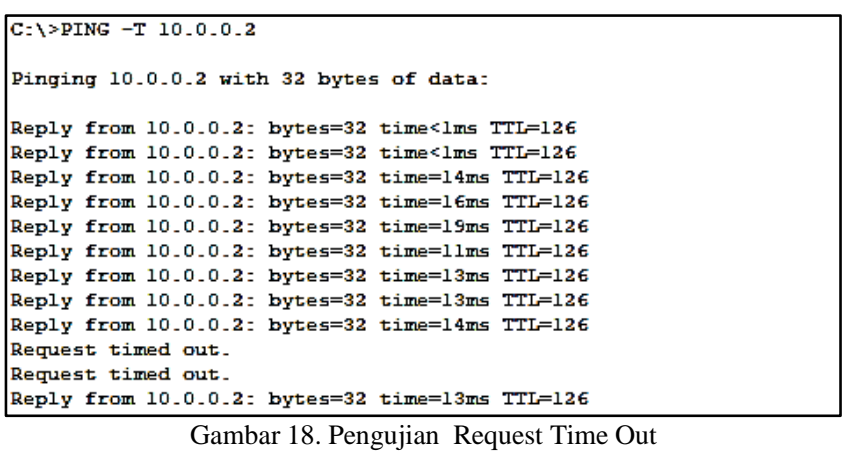

Namun walaupun transisi failover maupun recovery terlihat tanpa request time out, setiap kali terjadi failover maupun recovery, waktu pengiriman paket terlihat terjadi peningkatan.

Reply from 10.0 .0 .2 : bytes $=32$ time $<1 m s$ TII $=126$

Reply from 10.0.0.2: bytes $=32$ time $=1 m s$ TII $=126$

Reply from $10,0,0.2$ : bytes $=32$ time $=11 \mathrm{~ms}$ TTL $=126$

Reply from $10-0.0 .2$ : bytes $=32$ time $=12 \mathrm{~ms}$ TII $=126$

Reply from $10-0-0.2$ : bytes $=32$ time $=12 \mathrm{~ms}$ TTI $=126$

Reply from $10-0.0-2$ : bytes $=32$ time $=12 \mathrm{~ms}$.TI $=126$

Reply from $10-0-0.2$ : bytes $=32$ time $=13 m s$ TTI $=126$

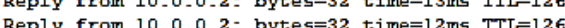

Reply from 10.0-0.2: bytes $=32$ time $=12 \mathrm{~ms}$ TIL $=126$

Reply from 10.0.0.2: bytes $=32$ time $=15$ ms TIL $=126$

Reply from 10.0.0.2: bytes=32 time $=15 m$ s $T I=126$

Reply from 10.0 .02 : bytes $=32$ time $=12 \mathrm{~ms}$ TIL $=12 \epsilon$
Reply from 10.0 .0 .2 : bytes $=32$ time $=13 \mathrm{~ms}$ TII $=12 \epsilon$

Gambar 19. Peningkatan Delay
Peningkatan ini hanya bersifat sementara sebelum akhirnya menjadi normal kembali, seperti terlihat pada Gambar 20. Kondisi Delay Normal Kembali di bawah ini:

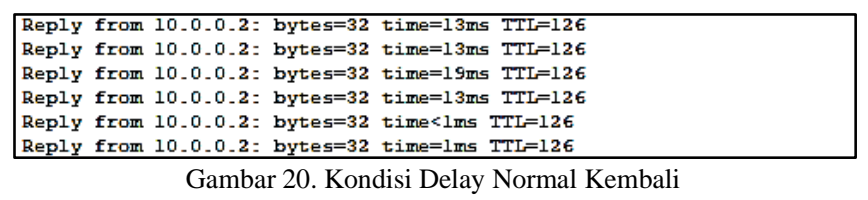

Cisco Packet Tracer yang digunakan tidak memiliki kemampuan analisis yang lebih mendalam dan tidak dapat digunakan bersama-sama dengan tools lain untuk menganalisis dan meng-capture data yang menggunakan Transport Control Protocol (TCP) dan User Datagram Protocol (UDP), sehingga analisis terhadap delay, jitter, Packet Loss dan Throughput tidak dapat dilakukan secara maksimal untuk merepresentasikan kondisi penggunaan perangkat fisik jaringan.

Satu-satunya protocol yang dapat digunakan sebagai analisis Quality of Service (QoS) pada Packet Tracer adalah menggunakan perintah ping yang menggunakan Internet Control Message Protocol (ICMP). Hal ini pun dirasa kurang untuk dapat merepresentasikan kondisi apabila menggunakan perangkat fisik jaringan, dikarenakan pada semua software simulasi jaringan kondisi seluruh perangkat akan dianggap selalu berada dalam kondisi ideal. Hal ini tentunya sangat jarang terjadi pada apabila jaringan dibuat dengan menggunakan perangkat fisik sungguhan.

Sehingga analisis yang dilakukan menggunakan perintah ping ini hanya dijadikan sebagai acuan dalam menganalisis Quality of Service $(Q o S)$ apabila konfigurasi yang sama dibangun menggunakan perangkat fisik sungguhan.

Analisis yang pertama dilakukan adalah analisis delay dengan menggunakan lamanya round trip time (RTT), yaitu waktu pengiriman paket sampai tujuan dan respon dari tujuan sampai kembali ke pengirim. Perhitungan yang dicari adalah waktu rata-rata round trip time dari banyaknya paket yang dikirim. Data waktu yang digunakan dapat dilihat pada Gambar 21. Sumber Data Delay.

\begin{tabular}{|c|c|c|}
\hline \multicolumn{3}{|c|}{$\begin{array}{l}\text { C:loping } 10.0 .0 .2 \text {-n } 100 \\
\text { Pinging } 10.0 .0 .2 \text { with } 32 \text { bytes of data: }\end{array}$} \\
\hline Reply from $10-0.0 .2=$ bytes $=32$ & time $<$ lms & $\mathrm{TL}=12 \epsilon$ \\
\hline Reply fram 10.0 .0 .2 : bytes $=32$ & time $<$ lms & $\mathrm{TL}=12 \epsilon$ \\
\hline Reply from $10.0-0.2$ : bytes $=32$ & time $=1 \mathrm{lms}$ & $T T L=12 \epsilon$ \\
\hline Reply from $10.0-0.2=$ bytes $=32$ & time $=10 \mathrm{~ms}$ & $T T L=12 \epsilon$ \\
\hline Reply from $10.0-0.2=$ bytes $=32$ & time $<$ lms : & $\mathrm{TI}=12 \epsilon$ \\
\hline Reply from 10.0 .0 .2 : bytes $=32$ & time $<$ lms & $\mathrm{TI}=12 \epsilon$ \\
\hline Reply from 10.0 .0 .2 : bytes $=32$ & time $<$ lms & $\mathrm{TI}=12 \epsilon$ \\
\hline Reply fram 10.0 .0 .2 : bytes $=32$ & time $<$ lms & $\mathrm{TL}=12 \epsilon$ \\
\hline Reply from 10.0 .0 .2 : bytes $=32$ & time $<$ lms & $\mathrm{FI}=12 \epsilon$ \\
\hline
\end{tabular}

Gambar 21. Sumber Data Delay 
Pengujian yang dilakukan adalah dengan mengirimkan paket ping sebanyak 100 kali dan memutuskan jalur utama sumber internet lalu menghidupkannya kembali, kemudian setelah kembali normal jalur yang dimatikan adalah jalur dalam jaringan lokal dan menghidupkannya kembali. Hal ini dilakukan sebanyak dua kali secara berurutan. Analisis dilakukan dengan menggunakan rumus:

$$
\text { Delay } \text { Rata-Rata }=\frac{\text { Total Delay }}{\text { Total Paket diterima }}
$$

Data yang memiliki nilai dibawah 1 milisecond (ms) dibulatkan menjadi $0 \mathrm{~ms}$. Hasil rata-rata delay yang didapat dari 100 kali pengiriman ping round trip time adalah $1.16 \mathrm{~ms}$.

Perhitungan jitter dilakukan menggunakan data yang sama dengan data perhitungan delay pada Gambar 21 Sumber Data Delay. Perhitungan delay dilakukan dengan mengambil data waktu round trip time, sedangkan pada perhitungan jitter yang diambil adalah selisih waktu round trip time pengiriman paket dari round trip time sebelumnya. Jitter yang merupakan fluktuasi nilai delay dalam suatu periode dihitung nilai rataratanya menggunakan rumus:

$$
\text { Jitter } \text { Rata-Rata }=\frac{\text { Total Variasi Delay }}{\text { Total Paket }}
$$

Hasil yang didapat adalah jitter yang dihasilkan memiliki waktu rata-rata sebesar $2.08 \mathrm{~ms}$.

Analisis berikutnya yang dilakukan adalah analisis terhadap packet loss, dimana pada analisis ini yang dilihat adalah banyaknya paket yang sampai ke tujuan dan berhasil memberikan respon serta paket yang tidak sampai tujuan atau respon yang tidak mencapai komputer pengirim. Rumus yang digunakan adalah:

$$
\text { Packet Loss }=\frac{\text { Paket Dikirim- Paket Diterima }}{\text { Paket Dikirim }} \times 100 \%
$$

Jumlah paket yang tidak berhasil diterima dapat diketahui

\begin{tabular}{|c|c|c|c|}
\hline Reply from 10_0_0_2: & bytes $=32$ & time $<$ lms & $T T L=12 \epsilon$ \\
\hline Reply from $10.0 .0 .2=$ & bytes $=32$ & time $<$ lms & $T I L=12 \epsilon$ \\
\hline Reply from $10.0 .0 .2=$ & bytes $=32$ & time $<$ lms & $T T L=12 \epsilon$ \\
\hline Reply from $10.0 .0 .2=$ & bytes $=32$ & time $<1 m s$ & $T T L=12 \epsilon$ \\
\hline Reply from $10.0 .0 .2=$ & bytes $=32$ & time $<$ lms & $T T L=12 \epsilon$ \\
\hline Realy from $1000.2=$ & bytes $=32$ & time $<1 m s$ & $T T L=12 \epsilon$ \\
\hline $\begin{array}{l}\text { Request timed out. } \\
\text { Request timed out. }\end{array}$ & & & \\
\hline 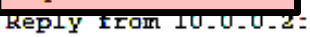 & bytes $=32$ & time $<$ lms & $T I L=12 \epsilon$ \\
\hline Reply from $10.0 .0 .2=$ & bytes $=32$ & time $<$ lms & $T T L=12 \epsilon$ \\
\hline
\end{tabular}
dari banyaknya paket ping dengan status request time out seperti terlihat pada gambar 22. Sumber Data Packet Loss.

Gambar 22. Sumber Data Packet Loss

Dari hasil perhitungan didapat persentase jumlah packet loss sebesar $3 \%$ dan request time out ini terjadi hanya jika jalur yang putus adalah jalur dari sumber internet.

Besarnya throughput atau kemampuan sebenarnya dari konfigurasi jaringan yang dibangun didapat dari jumlah total besarnya paket yang sukses dikirim dan direspon pada interval waktu pengiriman data tersebut. Interval waktu didapat dari lama waktu pengiriman data pertama dan terakhir, sehingga rumus yang digunakan adalah:

$$
\text { Throughput }=\frac{\text { jumlah bit diterima }}{\text { total waktu pengiriman }}
$$

Karena sumber data ping masih dalam satuan bytes maka perlu diubah terlebih dahulu menjadi bit dengan dikalikan dengan 8 bit untuk setiap byte, dan total waktu masih dalam

\begin{tabular}{|c|c|c|}
\hline \multirow{2}{*}{\multicolumn{3}{|c|}{$\begin{array}{l}\text { C: loping } 10.0 .0 .2-\mathrm{n} 100 \\
\text { Pinging } 10.0 .0 .2 \text { with } 32 \text { bytes of data: }\end{array}$}} \\
\hline & & \\
\hline Reply from 10.0 .0 .2 & bytes $=32$ time $<$ lms : & $\mathrm{TI}=12 \epsilon$ \\
\hline Reply from 10.0 .0 .2 & bytes $=32$ time $<$ lms : & $\mathrm{TI}=12 \epsilon$ \\
\hline Reply from $10.0 .0 .2=$ & bytes $=32$ time $=1 \mathrm{lms}$ & $T T L=12 \epsilon$ \\
\hline Reply from $10.0 .0 .2=$ & bytes $=32$ time $=10 \mathrm{~ms}$ & $T T L=12 \epsilon$ \\
\hline Reply from 10.0 .0 .2 & bytes $=32$ time $<$ lms : & $\mathrm{TI}=12 \epsilon$ \\
\hline Reply fram 10.0 .0 .2 & bytes $=32$ time $<$ lms : & $T I=12 \epsilon$ \\
\hline Reply from 10.0 .0 .2 & bytes $=32$ time $<$ lms & $\mathrm{TI}=12 \epsilon$ \\
\hline Reply from 10.0 .0 .2 & bytes $=32$ time $<$ lms : & $T I=12 \epsilon$ \\
\hline Reply from $10.0 .0 .2=$ & bytes $=32$ time $<$ lms: & $\mathrm{TI}=12 \epsilon$ \\
\hline
\end{tabular}
satuan milisecond (ms) sehingga perlu dibagi dengan 1000 terlebih dahulu baru dilakukan perhitungan menggunakan rumus yang ada.

Gambar 23. Sumber Data Throughput

Hasil througput yang didapat adalah sebesar 220.689,7 bit per second (bps) atau sama dengan 220,6 kilo bit per second (kbps).

Hasil analisis ini merupakan hasil dari simulasi jaringan sehingga tidak menggambarkan kualitas jaringan apabila konfigurasi yang sama dibangun menggunakan perangkat jaringan fisik. Apabila konfigurasi yang sama dibangun menggunakan perangkat keras fisik, sebaiknya gunakan tools tambahan seperti wireshark yang dapat merekam data lalu lintas jaringan TCP dan UDP. Analisa hasil rekaman lalu lintas data yang didapat dari wireshark dilakukan analisa menggunakan cara dan rumus yang sama untuk mendapatkan nilai Quality of Service (Qos) seperti delay, jitter, packet loss, dan throughput.

\section{SIMPULAN}

Berdasarkan keseluruhan hasil simulasi dan pengujian didapati bahwa load balancing pada redundancy link HSRP dapat dilakukan dengan membagi setiap VLAN yang digunakan ke dalam group HSRP yang diwakili oleh subinterface sebanyak jumlah VLAN yang digunakan. Akan tetapi failover dan recovery akan memerlukan waktu lebih lama apabila yang mengalami permasalahan adalah bagian 
interface yang memiliki multigroup atau banyak subinterface dibanding dengan waktu failover dan recovery pada satu interface fisik yang mengarah ke jaringan di luar VLAN yang digunakan. Proses transisi ketika terjadi failover dan recovery sangat jarang mengalami packet missing atau time out namun terjadi penambahan delay pada proses pengiriman data selama beberapa saat, sebelum akhirnya berjalan normal kembali.

Sangat disarankan untuk melakukan konfigurasi jaringan yang sama menggunakan peralatan fisik dan tool seperti wireshark yang dapat digunakan untuk merekam data lalu lintas jaringan menggunakan TCP dan UDP sehingga mendapatkan hasil analisis QoS yang lebih akurat sesuai dengan kualitas dan kondisi hardware yang digunakan.

\section{DAFTAR PUSTAKA}

[1] P. Firmansyah, Wahyudi, M \& Rachmat, "Analisis Perbandingan Kinerja Jaringan CISCO Virtual Router Redundancy Protocol (VRRP) Dan CISCO Hot Standby Router Protocol (HSRP)," Tek. Komput. AMIK BSI Tegal, vol. 1, no. 1, pp. 764-769, 2018.

[2] A. Akmaludin, A. Mt, S. U. Masruroh, and M. Sc, "Evaluasi Kinerja Hot Standby Router Protocol (HSRP) dan Gateway Load Balancing Protocol (GLBP) untuk Layanan Video Streaming," CyberSecurity dan Forensik Digit., vol. 2, no. 1, pp. 43-51, 2019.

[3] Cisco, "First Hop Redundancy Protocols Configuration Guide, Cisco IOS XE Release 3S - HSRP MD5 Authentication [Cisco IOS XE 3S]," Cisco, no. 6387, 2018.

[4] P. Dubey, S. Sharma, and A. Sachdev, "Review of first hop redundancy protocol and their functionalities," Int. J. Eng. Trends Technol., vol. 4, no. 5, pp. 1085-1088, 2013.

[5] Y. Haiyan, "Application of Vlan and HSRP Technology in the Dual Core Campus Network," Proc. - 2018 Int. Conf. Smart Grid Electr. Autom. ICSGEA 2018, pp. 332-333, 2018, doi: 10.1109/ICSGEA.2018.00088.

[6] A. K. Singh and A. Kothari, "HSRP (Hot Stand by Routing Protocol) reliability issues over the Internet service provider's network," Orient. J. Comput. Sci. Technol., vol. 4, no. 2, 2011.

[7] U. Anwar, "Performance Analysis and Functionality Comparison of FHRP Protocols," 2019 IEEE 11 th Int. Conf. Commun. Softw. Networks, pp. 111-115, 2019, doi: 10.1109/ICCSN.2019.8905333.

[8] M. Mansour, "Performance Evaluation of First Hop Redundancy Protocols," Procedia Comput. Sci., vol. 177, pp. 330-337, 2020, doi: 10.1016/j.procs.2020.10.044.

[9] Z. U. Rahman et al., "Performance Evaluation of First HOP Redundancy Protocols ( HSRP, VRRP \& GLBP )," J . Appl . Env. . Biol. Sci, vol. 7, no. 3, pp. 268-278, 2017.

[10] V. Nirmala and A. Sridevi, "Packet Delivery and Numerous Redundancies in Ipv4 Network through GLBP," J. Chem. Pharm. Sci., no. 8, pp. 146-148, 2016.

[11] Cisco, Campus Network for High Availability Design Guide Cisco. Cisco Systems, Inc, 2008. 